\title{
Effects of Human Resource Management and Knowledge Sharing on Turnover Intention in the Beauty Service Industry
}

Jung-Eun Park, Eun-Jun Park

Department of Beauty Art, Seokyeong University, Seoul, Korea

\author{
"Corresponding author: Eun-Jun Park, \\ Department of Beauty Art, Seokyeong \\ University, 124 Seogyeong-ro, Seongbuk- \\ gu, Seoul 02713, Korea \\ Tel.: +82 29457823 \\ Fax: +82 29457823 \\ Email: ayamdream@hanmail.net
}

Received March 22, 2017

Revised May 21, 2017

Accepted May 29, 2017

Published September 30, 2017

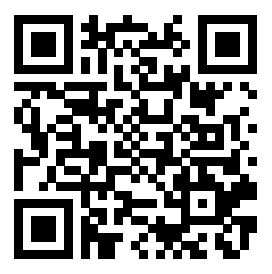

\begin{abstract}
Purpose: This study intended to investigate the effects of human resource management and knowledge sharing on turnover intention in the beauty service industry. Methods: Data were collected from workers in the beauty service industry and analyzed using Statistical Package for the Social Sciences (SPSS) 22.0. The collected data were processed through frequency analysis, factor analysis, reliability analysis, and multiple regression analysis. Results: The results showed that human resource management factors, such as education management, work management, compensation management, and employment management had significant effects on turnover intention for the same field or different fields. Also, knowledge sharing factors, such as knowledge storing, structuring sharing, relational sharing, and personal sharing significantly influenced the turnover intention for the same field or different fields. Conclusion: It is hoped that the results of this study will provide basic data for the development of the beauty service industry, showing that it is necessary to recognize the importance of human resource management and knowledge sharing as a way to reduce turnover in the beauty service industry and map out systematic strategic measures.
\end{abstract}

Keywords: Beauty, Service industry, Human resource management, Knowledge sharing, Turnover intention

\section{Introduction}

오늘날 현대의 미용서비스업은 고부가가치 사업으로 미용서비 스업의 시장은 급격히 확대되었으며, 업체 간의 경쟁이 격화되고, 기업은 경쟁우위 확보를 위한 경영전략이 필요한 실정이다.

미용서비스업은 서비스업의 특성상 고객과의 접점이 중요시 되 며 종사자들의 역할이 중요하다. 이 중 종사자들의 이직은 고객 불만족으로 이어지고 기업의 매출감소 원인이 된다. 종사자들의 이직의도는 기업의 종사자가 현재 근무하는 기업을 떠나고 싶다 고 생각하는 정도나 근무할 수 있는 새로운 기업이 있는지 알아보 는 잠재적인 의사 정도를 말하며(Jun, 2003), 기업은 이직률을 줄 이기 위한 다양한 방안들을 수립하여야 한다.

최근 많은 기업들 사이에서는 기업의 경쟁력을 높이기 위한 수 단으로 인적자원관리와 종사원간 지식공유의 중요성을 인식하고 기업의 주요 과제로 다루고 있다. 인적자원관리는 기업의 종사자 들의 인사 및 성과에 대한 배분, 업무성과의 평가 및 보상, 종사 자의 업무배치 등을 문서로써 명백히 하여 일관되게 적용하는 것
을 의미하며(Kim \& Kim, 1999), 지식공유는 기업의 종사자들이 지식을 서로 공개하고 기업 내에서 이를 확산하고 저장하여 활용 함으로써 기업의 가치와 효율성을 증대시키는 행위를 의미한다 (Kim \& Kang, 2004).

인적자원관리에 관한 연구로 Song \& Kim (2011)은 전략적 인 적자원관리 시스템이 지적 자본과 혁신역량에 미치는 영향을 연 구하여 인적자원관리 시스템은 지적 자본의 개발과 축적에 근본 적인 것임을 제시하였고, Song \& Na (2014)는 테크노파크 조직 의 인적자원관리 구성요소가 직무만족에 미치는 영향을 분석한 결과 직무평가가 가장 중요한 요인임을 밝혔다. 지식공유에 관한 연구로는 Moon (2005)이 간호사의 지식공유가 혁신행동과 조직 몰입에 미치는 영향을 연구하여 지식공유는 조직성과를 향상시 킬 수 있는 혁신행동과 조직몰입에 영향을 미치는 중요한 변수임 을 확인하였으며, Choi \& Park (2012)은 중소기업의 협력활동과 지식공유가 기업경쟁력에 미치는 영향을 연구하여 기업간 지식공 유는 기업경쟁력에 긍정적인 영향을 미치는 것을 확인하였다. 이 처럼 인적자원관리와 지식공유에 관한 다양한 연구들이 이루어져 
있지만, 미용서비스업의 인적자원관리와 지식공유에 관한 연구는 미비한 실정이다.

이에 본 연구는 인적자원관리와 지식공유가 미용서비스업의 이 직의도에 미치는 영향 관계를 알아보고 미용서비스업에서의 이직 률을 줄이기 위한 방안을 제시하는데 그 목적이 있다.

\section{Methods}

\section{1. 연구대상 및 자료수집}

본 연구는 미용서비스업의 종사자를 대상으로 설문조사를 실시 하였다. 조사기간은 2016년 5월 4일부터 6월 20일까지 48일간이 었으며, 자기기입식 설문지법이 사용되었다. 총 730 부의 설문지 를 배부하여 712 부를 회수하였으며, 분석 자료로 불충분한 12 부를 제외한 700 부의 설문지가 최종 분석에 사용되었다.

\section{2. 연구내용 및 방법}

\section{1) 설문지구성}

설문지는 일반적 특성 10 문항, 인적자원관리 17 문항, 지식공유 15 문항, 이직의도 9 문항으로 총 51 문항으로 구성하여 설문을 실 시하였다. 일반적 특성은 연구자 구성으로 명명척도를 사용하였 다. 인적자원관리는 Cha \& Chang (2010), Kim et al. (2015)의 연구에서 인용된 척도를 본 연구에 맞게 수정 보완하여 구성하였 으며, 지식공유는 Eom (2014)의 연구에서 인용된 척도를 본 연구 에 맞게 수정 보완하여 구성하였고, 이직의도는 Kang \& Jyung (2015), Shin et al. (2015)의 연구에서 인용된 척도를 본 연구에 맞게 수정 보완하였다. 각 문항은 1점 '매우 그렇지 않다'에서 5점 '매우 그렇다'로 5점 리커트 척도로 측정하였다.

\section{2) 자료분석방법}

본 연구의 수집된 자료는 SPSS 22.0 (IBM, USA)을 이용하여 분석하였다. 조사대상의 일반적 특성은 빈도분석을 하였다. 인적 자원관리, 지식공유, 이직의도의 각 차원을 알아보기 위해 요인분 석과 신뢰도분석을 하였으며, 인적자원관리, 지식공유, 이직의도 의 영향 관계를 알아보기 위해 다중회귀분석을 하였다.

\section{Results and Discussion}

\section{1. 조사대상의 일반적 특성}

조사대상인 미용서비스업 종사자의 일반적 특성을 알아보기 위 해 빈도분석을 실시한 결과는 Table 1과 같다.

성별은 남성 $12.0 \%$, 여성 $88.0 \%$ 로 여성이 높게 나타났고, 연령 은 10 대 $1.7 \%, 20$ 대 $76.4 \%, 30$ 대 $14.4 \%, 40$ 대 $6.1 \%, 50$ 대 이상
$1.3 \%$ 로 20 대가 가장 높게 나타났다. 결혼여부의 경우 미혼 $85.6 \%$, 기혼 $13.3 \%$, 이혼 $1.1 \%$ 로 미혼이 가장 높게 나타났다. 학력을 알 아본 결과 고등학교 졸업 $14.7 \%$, 전문대학 재학/졸업 $26.4 \%$, 대학 교 재학/졸업 $50.9 \%$, 대학원 재학/졸업 $8.0 \%$ 로 대학교 재학/졸업 이 가장 높게 나타났다. 직급은 인턴(어시스트) $48.1 \%$, 디자이너(실 무자) $33.9 \%$, 실장(점장) $7.1 \%$, 원장(대표) $6.9 \%$, 매니저 $4.0 \%$ 로 인턴(어시스트)가 가장 높게 나타났다. 급여형태를 알아본 결과 급 여 $68.6 \%$, 인센티브 $24.1 \%$, 기타 $7.3 \%$ 로 급여가 가장 높게 나타났 다. 미용경력은 3년 이하 $61.6 \%, 4-6$ 년 17.3\%, 7-9년 9.6\%, 10-12 년 $4.7 \%, 13$ 년 이상 $6.9 \%$ 로 3 년 이하가 가장 높게 나타났다. 회사 형태로는 프랜차이즈 $57.7 \%$, 개인 $38.4 \%$, 기타 $3.9 \%$ 로 프랜차이 즈가 가장 높게 나타났으며, 직원 수는 5명 이하 26.3\%, 6-10명 $34.4 \%, 11-15$ 명 22.9\%, 16-20명 7.0\%, 21명 이상 9.4\%로 6-10명이 가장 높게 나타났다. 미용분야를 알아본 결과 헤어 $72.0 \%$, 메이크 업 $3.4 \%$, 피부관리 $17.4 \%$, 네일아트 $4.0 \%$, 기타 $3.1 \%$ 로 헤어가 가 장 높게 나타났다.

\section{2. 인적자원관리, 지식공유, 이직의도의 타당성 및 신뢰도}

본 연구에서 사용된 측정항목에 대해 타당성을 검증하고, 공 통요인을 찾아내 변수로 활용하기 위해 탐색적 요인분석(factor analysis)을 실시하였으며, 요인추출법으로 주성분법(principal components)을 실시하였다. 요인회전과 관련하여, 요인을 단순화 하기 위해 일반적으로 널리 사용되는 방법인 베리멕스(varimax)회 전을 이용하였다. 요인분석은 분석방법의 특성상 각 항목들 간의 상관관계가 높아야 하는데, Kaise-Meyer-Olkin (KMO) 측도와 Bartlett의 구형성 검정은 각 항목들 간의 상관행렬을 확인함으로써 사용 항목들이 요인분석에 적합한가를 나타내주는 방법이다. $\mathrm{KMO}$ 는 변수쌍들 간의 상관관계가 다른 변수에 의해 잘 설명되는 정보 를 나타내는 것이므로, 이 측도의 값이 작으면 요인분석을 위한 변 수 선정이 좋지 않음을 나타낸다. 또한 본 연구에서 다 문항 척도로 측정된 문항이 동질적인 문항들로 구성되었는지 신뢰도를 검증하기 위해 문항간의 내적 일치도를 보는 Cronbach's $\alpha$ 값을 산출하였다.

\section{1) 인적자원관리의 차원}

인적자원관리 문항에 대해 요인분석을 이용한 타당성 검증결 과 Table 2 와 같이 네 개의 요인이 도출되었다. Bartlett의 단위 행렬 점검 결과 $\chi^{2}=7553.039$ [degrees of freedom (df)=136; significance $(\mathrm{Sig})=0.000], \mathrm{KMO}$ 값 0.930 으로 나타났으며, 공 통성은 0.582 이상으로 나타났다.

첫 번째 요인은 '교육관리' 요인으로 요인적재값은 0.7650.814 로 나타났으며, 고유값은 3.222 , 분산설명비율은 $19.0 \%$ 으로 나타났다. 두 번째 요인은 '직무관리' 요인으로 요인적재값 은 0.554-0.812로 나타났으며, 고유값은 3.219, 분산설명비율은 $18.9 \%$ 로 나타났다. 세 번째 요인은 '보상관리' 요인으로 요인적재 
값은 0.735-0.805로 나타났으며, 고유값은 3.138, 분산설명비율 은 $18.5 \%$ 로 나타났다. 네 번째 요인은 '채용관리' 요인으로 요인
적재값은 0.623-0.839로 나타났으며, 고유값은 2.690, 분산설명 비율은 $15.8 \%$ 로 나타났다. 요인분석 결과 도출된 네 개의 요인이

Table 1. General characteristics of participants

\begin{tabular}{|c|c|c|c|}
\hline \multirow{2}{*}{ Items } & & \multicolumn{2}{|c|}{ Total } \\
\hline & & Frequency $(\mathrm{N})$ & Percentage (\%) \\
\hline \multirow{2}{*}{ Gender } & Men & 84 & 12.0 \\
\hline & Women & 616 & 88.0 \\
\hline \multirow{5}{*}{ Age } & Teenager & 12 & 1.7 \\
\hline & $20 \mathrm{~s}$ & 535 & 76.4 \\
\hline & $30 \mathrm{~s}$ & 101 & 14.4 \\
\hline & $40 \mathrm{~s}$ & 43 & 6.1 \\
\hline & 50 s or older & 9 & 1.3 \\
\hline \multirow{3}{*}{ Marital status } & Single & 599 & 85.6 \\
\hline & Married & 93 & 13.3 \\
\hline & Divorced & 8 & 1.1 \\
\hline \multirow{4}{*}{ Education level } & Graduated from high school & 103 & 14.7 \\
\hline & Currently attending or graduated from college & 185 & 26.4 \\
\hline & Currently attending or graduated from university & 356 & 50.9 \\
\hline & Currently attending or graduated from graduate school & 56 & 8.0 \\
\hline \multirow{5}{*}{ Post } & Intern (assistant) & 337 & 48.1 \\
\hline & Designer (working-level) & 237 & 33.9 \\
\hline & Director (branch representative) & 50 & 7.1 \\
\hline & Chairman (representative) & 48 & 6.9 \\
\hline & Manager & 28 & 4.0 \\
\hline \multirow{3}{*}{ Type of wage } & Wage & 480 & 68.6 \\
\hline & Incentive & 169 & 24.1 \\
\hline & Others & 51 & 7.3 \\
\hline \multirow{5}{*}{ Beauty career } & 3 years or less & 431 & 61.6 \\
\hline & $4-6$ years & 121 & 17.3 \\
\hline & $7-9$ years & 67 & 9.6 \\
\hline & $10-12$ years & 33 & 4.7 \\
\hline & 13 years or more & 48 & 6.9 \\
\hline \multirow{3}{*}{ Type of company } & Franchise & 404 & 57.7 \\
\hline & Private enterprise & 269 & 38.4 \\
\hline & Others & 27 & 3.9 \\
\hline \multirow{5}{*}{ No. of employees } & 5 persons or less & 184 & 26.3 \\
\hline & $6-10$ persons & 241 & 34.4 \\
\hline & $11-15$ persons & 160 & 22.9 \\
\hline & $16-20$ persons & 49 & 7.0 \\
\hline & 21 persons or more & 66 & 9.4 \\
\hline \multirow{5}{*}{ Beauty field } & Hair & 504 & 72.0 \\
\hline & Makeup & 24 & 3.4 \\
\hline & Skin care & 122 & 17.4 \\
\hline & Nail art & 28 & 4.0 \\
\hline & Others & 22 & 3.1 \\
\hline Total & & 700 & 100.0 \\
\hline
\end{tabular}


전체 분산의 $72.1 \%$ 이상 설명되고 있는 것으로 나타났다.

인적자원관리에 대한 신뢰성 검증 결과, 신뢰도 계수인 Cronbach's $\alpha$ 는 0.834-0.900으로 높게 나타나, 신뢰성에는 문제 가 없는 것으로 나타났다. 요인 별로 살펴보면, 교육관리 0.900 , 직무관리 0.870 , 보상관리 0.893 , 채용관리 0.834 로 나타났다.

\section{2) 지식공유의 차원}

지식공유 문항에 대해 요인분석을 이용한 타당성 검증결과 Table 3 과 같이 네 개의 요인이 도출되었다. Bartlett의 단위행렬 점검 결과 $\chi^{2}=7407.011(\mathrm{df}=105 ; \mathrm{Sig}=0.000), \mathrm{KMO}$ 값 0.921으 로 나타났으며, 공통성은 0.677 이상으로 나타났다.

첫 번째 요인은 '지식저장' 요인으로 요인적재값은 0.780-
0.805 로 나타났으며, 고유값은 3.034 , 분산설명비율은 $20.2 \%$ 로 나타났다. 두 번째 요인은 '구조적 공유' 요인으로 요인적재값은 0.729-0.810으로 나타났으며, 고유값은 2.992, 분산설명비율은 $19.9 \%$ 로 나타났다. 세 번째 요인은 '관계적 공유' 요인으로 요인적 재값은 0.666-0.833으로 나타났으며, 고유값은 2.969, 분산설명 비율은 $19.8 \%$ 로 나타났다. 네 번째 요인은 '개인적 공유' 요인으로 요인적재값은 0.798-0.859으로 나타났으며, 고유값은 2.538, 분 산설명비율은 $16.9 \%$ 로 나타났다. 요인분석 결과 도출된 네 개의 요인이 전체 분산의 $76.8 \%$ 이상 설명되고 있는 것으로 나타났다.

지식공유에 대한 신뢰성 검증 결과, 신뢰도 계수인 Cronbach' $\mathrm{s} \alpha$ 는 0.878-0.894로 높게 나타나, 신뢰성에는 문제가 없는 것으 로 나타났다. 요인별로 살펴보면, 지식저장 0.878 , 구조적 공유

Table 2. Dimensions of human resource management

\begin{tabular}{|c|c|c|c|c|}
\hline \multirow[b]{2}{*}{ Questions related to human resources management } & Factor 1 & Factor 2 & Factor 3 & Factor 4 \\
\hline & $\begin{array}{l}\text { Education } \\
\text { management }\end{array}$ & $\begin{array}{c}\text { Work } \\
\text { management }\end{array}$ & $\begin{array}{c}\text { Compensation } \\
\text { management }\end{array}$ & $\begin{array}{l}\text { Employment } \\
\text { management }\end{array}$ \\
\hline $\begin{array}{l}\text { My company offers employees opportunities for various } \\
\text { education and training programs in connection with work. }\end{array}$ & 0.814 & 0.198 & 0.210 & 0.212 \\
\hline $\begin{array}{l}\text { My company makes much investment in } \\
\text { education and training of employees. }\end{array}$ & 0.810 & 0.215 & 0.154 & 0.248 \\
\hline $\begin{array}{l}\text { My companies provide employees with longer hours of } \\
\text { education and training, compared to other companies } \\
\text { in the same industry. }\end{array}$ & 0.791 & 0.208 & 0.239 & 0.201 \\
\hline $\begin{array}{l}\text { My company has a systematic education and training } \\
\text { program which employees can participate in. }\end{array}$ & 0.765 & 0.182 & 0.166 & 0.285 \\
\hline $\begin{array}{l}\text { Employees of my company participate extensively in decision- } \\
\text { making and problem-solving processes related to their work } \\
\text { and working environment. }\end{array}$ & 0.147 & 0.812 & 0.248 & 0.152 \\
\hline $\begin{array}{l}\text { My company devolves authorities and responsibilities } \\
\text { extensively to employees. }\end{array}$ & 0.152 & 0.811 & 0.179 & 0.141 \\
\hline $\begin{array}{l}\text { My company empowers employees greatly, giving them much } \\
\text { discretion. }\end{array}$ & 0.121 & 0.731 & 0.376 & 0.176 \\
\hline $\begin{array}{l}\text { My company introduced and operates a team system actively } \\
\text { for effective performance of work. }\end{array}$ & 0.301 & 0.682 & 0.192 & 0.119 \\
\hline $\begin{array}{l}\text { In my company, feedback and coaching occur among superiors/ } \\
\text { colleagues smoothly. }\end{array}$ & 0.346 & 0.554 & 0.351 & 0.180 \\
\hline $\begin{array}{l}\text { In my company, wage determination criteria are reasonable, } \\
\text { transparent, and fair. }\end{array}$ & 0.192 & 0.291 & 0.805 & 0.179 \\
\hline $\begin{array}{l}\text { My company pays wages relatively higher than those of other } \\
\text { companies in the same industry. }\end{array}$ & 0.172 & 0.182 & 0.801 & 0.232 \\
\hline I am paid a fair wage for the efforts that I am making. & 0.199 & 0.310 & 0.776 & 0.112 \\
\hline $\begin{array}{l}\text { My company is operating a system that distributes company } \\
\text { profits to employees (collective performance-relayed pay } \\
\text { system, profit-sharing system, etc.). }\end{array}$ & 0.234 & 0.316 & 0.735 & 0.169 \\
\hline $\begin{array}{l}\text { My company has proper screening procedures such as tests, } \\
\text { interviews, etc., for employment. }\end{array}$ & 0.170 & 0.082 & 0.103 & 0.839 \\
\hline $\begin{array}{l}\text { My company sets forth clear selection criteria related to skill } \\
\text { and ability for employment. }\end{array}$ & 0.247 & 0.128 & 0.178 & 0.783 \\
\hline $\begin{array}{l}\text { My company considers skills and attitude important for } \\
\text { employment. }\end{array}$ & 0.205 & 0.251 & 0.147 & 0.714 \\
\hline $\begin{array}{l}\text { My company invests much time and financial resources in the } \\
\text { screening process in order to select excellent candidates. }\end{array}$ & 0.362 & 0.184 & 0.309 & 0.623 \\
\hline Unique value & 3.222 & 3.219 & 3.138 & 2.690 \\
\hline Explained variance (\%) & 18.955 & 18.936 & 18.458 & 15.824 \\
\hline Cumulative variance (\%) & 18.955 & 37.891 & 56.349 & 72.173 \\
\hline Reliability coefficient (Cronbach's $\alpha$ ) & 0.900 & 0.870 & 0.893 & 0.834 \\
\hline
\end{tabular}


0.894 , 관계적 공유 0.889 , 개인적 공유 0.891 로 나타났다.

\section{3) 이직의도의 차원}

이직의도 문항에 대해 요인분석을 이용한 타당성 검증결과 Table 4 와 같이 두 개의 요인이 도출되었다. Bartlett의 단위행렬 점검 결과 $\chi^{2}=5471.206(\mathrm{df}=36 ; \mathrm{Sig}=0.000), \mathrm{KMO}$ 값 0.928 으 로 나타났으며, 공통성은 0.624 이상으로 나타났다.

첫 번째 요인은 '동일분야 이직의도' 요인으로 요인적재값은 0.704-0.846으로 나타났으며, 고유값은 3.667, 분산설명비율은 $40.7 \%$ 로 나타났다. 두 번째 요인은 '타분야 이직의도' 요인으로 요인적재값은 $0.780-0.866$ 으로 나타났으며, 고유값은 3.242 , 분 산설명비율은 $38.0 \%$ 로 나타났다. 요인분석 결과 도출된 두 개의 요인이 전체 분산의 $78.7 \%$ 이상 설명되고 있는 것으로 나타났다.

이직의도에 대한 신뢰성 검증 결과, 신뢰도 계수인 Cronbach's $\alpha$ 는 0.914 이상으로 높게 나타나, 신뢰성에는 문제가 없는 것으로 나타났다. 요인별로 살펴보면, 동일분야 이직의도 0.914 , 타분야 이직의도 0.933 으로 나타났다.

\section{3. 인적자원관리가 이직의도에 미치는 영향}

1) 인적자원관리가 동일분야 이직의도에 미치는 영향

인적자원관리의 하위요인들이 이직의도의 하위요인인 동일분 야 이직의도에 미치는 영향에 대한 회귀분석 결과는 Table 5 와 같 다. 교육관리, 직무관리, 보상관리, 채용관리에서 유의미하게 영 향을 미치는 것으로 나타났고, 교육관리, 직무관리, 보상관리, 채용관리 변수가 동일분야 이직의도 요인을 예측하는데 $29.0 \%$ 의 설명력을 갖는 것으로 나타났다. 독립변수의 영향력을 살펴보 면 교육관리, 직무관리, 보상관리, 채용관리 변수가 유의미하게 $(p<0.001)$ 부(-)적으로 영향을 미치는 것으로 나타났다. 이는 교 육관리, 직무관리, 보상관리, 채용관리가 높아질수록 동일분야 이직의도는 낮아지고 있음을 의미한다. 각 변수의 영향력을 살 펴보면 보상관리( $\beta=-0.422)$, 직무관리 $(\beta=-0.236)$, 교육관리( $\beta$ $=-0.181)$, 채용관리 $(\beta=-0.166)$ 순으로 크게 영향을 미치는 것으 로 나타났다. 이러한 결과는 전략적 인적자원관리가 이직의도를 낮춘다는 Cho \& Yoon (2013)의 연구와 유사함을 확인하였다.

Table 3. Dimensions of knowledge sharing

\begin{tabular}{|c|c|c|c|c|}
\hline & Factor 1 & Factor 2 & Factor 3 & Factor 4 \\
\hline Questions related to knowledge sharing & $\begin{array}{l}\text { Knowledge } \\
\text { storing }\end{array}$ & $\begin{array}{l}\text { Structuring } \\
\text { sharing }\end{array}$ & $\begin{array}{l}\text { Relational } \\
\text { sharing }\end{array}$ & $\begin{array}{l}\text { Personal } \\
\text { sharing }\end{array}$ \\
\hline $\begin{array}{l}\text { I make up for opinions or materials } \\
\text { /data after using the knowledge. }\end{array}$ & 0.805 & 0.189 & 0.263 & 0.196 \\
\hline I classify acquired knowledge systematically. & 0.792 & 0.183 & 0.219 & 0.151 \\
\hline $\begin{array}{l}\text { I document my know-how, failures, } \\
\text { problem-solving procedures, etc. }\end{array}$ & 0.792 & 0.249 & 0.067 & 0.184 \\
\hline I update my knowledge constantly. & 0.780 & 0.193 & 0.174 & 0.213 \\
\hline $\begin{array}{l}\text { My current company tends to be accepted more relatively by } \\
\text { employees in terms of evaluation and reward/compensation. }\end{array}$ & 0.215 & 0.810 & 0.319 & 0.156 \\
\hline $\begin{array}{l}\text { My company creates a learning environment } \\
\text { to expand learning of content service. }\end{array}$ & 0.245 & 0.801 & 0.188 & 0.195 \\
\hline $\begin{array}{l}\text { Employees of my company are given proper compensation/reward } \\
\text { for their achievements, level of responsibilities, and results of efforts. }\end{array}$ & 0.262 & 0.735 & 0.296 & 0.172 \\
\hline $\begin{array}{l}\text { My company tends to give constant support and } \\
\text { considerations actively for knowledge-sharing. }\end{array}$ & 0.194 & 0.729 & 0.317 & 0.259 \\
\hline $\begin{array}{l}\text { My company usually makes effort to help maintain } \\
\text { interpersonal relationship among colleagues. }\end{array}$ & 0.178 & 0.263 & 0.833 & 0.218 \\
\hline $\begin{array}{l}\text { In my company, colleagues to have a full understanding } \\
\text { during their discussions about work. }\end{array}$ & 0.200 & 0.229 & 0.819 & 0.150 \\
\hline $\begin{array}{l}\text { In my company, trust among superiors } \\
\text { /colleagues tends to be strong. }\end{array}$ & 0.181 & 0.339 & 0.723 & 0.240 \\
\hline $\begin{array}{l}\text { In our organization, colleagues are very } \\
\text { cooperative in knowledge-sharing. }\end{array}$ & 0.228 & 0.295 & 0.666 & 0.308 \\
\hline $\begin{array}{l}\text { I share with colleagues the knowledge that I acquire } \\
\text { from business travel or education/training, etc. }\end{array}$ & 0.217 & 0.206 & 0.212 & 0.859 \\
\hline $\begin{array}{l}\text { I share with colleagues the work-related } \\
\text { knowledge that I learned personally. }\end{array}$ & 0.261 & 0.235 & 0.228 & 0.802 \\
\hline $\begin{array}{l}\text { I share with colleagues the materials, manuals, documents, } \\
\text { etc., which are necessary for performance of work. }\end{array}$ & 0.203 & 0.180 & 0.256 & 0.798 \\
\hline Unique value & 3.034 & 2.992 & 2.969 & 2.538 \\
\hline Explained variance (\%) & 20.228 & 19.948 & 19.794 & 16.918 \\
\hline Cumulative variance $(\%)$ & 20.228 & 40.176 & 59.970 & 76.889 \\
\hline Reliability coefficient (Cronbach's $\alpha$ ) & 0.878 & 0.894 & 0.889 & 0.891 \\
\hline
\end{tabular}


2) 인적자원관리가 타분야 이직의도에 미치는 영향

인적자원관리의 하위요인들이 이직의도의 하위요인인 타분 야 이직의도에 미치는 영향에 대한 회귀분석 결과는 Table 6과 같다. 교육관리, 직무관리, 보상관리, 채용관리에서 유의미하게 영향을 미치는 것으로 나타났고 교육관리, 직무관리, 보상관리, 채용관리 변수가 타분야 이직의도 요인을 예측하는데 $13.5 \%$ 의 설명력을 갖는 것으로 나타났다. 독립변수의 영향력을 살펴보 면 교육관리, 직무관리, 보상관리 변수가 유의미하게 $(p<0.001)$ 부(-)적으로 영향을 미치는 것으로 나타났고, 채용관리 변수가 유의미하게 $(p<0.05)$ 부(-)적으로 영향을 미치는 것으로 나타났
다. 이는 교육관리, 직무관리, 보상관리, 채용관리가 높아질수 록 타분야 이직의도는 낮아지고 있음을 의미한다. 각 변수의 영 향력을 살펴보면 직무관리 $(\beta=-0.264)$, 교육관리 $(\beta=-0.191)$, 보상관리 $(\beta=-0.160)$, 채용관리 $(\beta=-0.088)$ 순으로 크게 영향 을 미치는 것으로 나타났다. 이러한 결과는 고몰입 인적자원 관리는 직무만족 및 이직의도에 긍정적인 영향을 주고 있다는 Nam \& Chun (2012)의 연구와 유사함을 확인하였다.

\section{4. 지식공유가 이직의도에 미치는 영향}

1) 지식공유가 동일분야 이직의도에 미치는 영향

\section{Table 4. Dimensions of turnover intention}

\begin{tabular}{lcc}
\hline & Factor 1 & Factor 2 \\
Questions related to turnover intention & $\begin{array}{c}\text { Turnover intention } \\
\text { for the same field }\end{array}$ & $\begin{array}{c}\text { Turnover intention } \\
\text { for different fields }\end{array}$ \\
\cline { 2 - 3 } I want to work in other companies. & 0.846 & 0.326 \\
If other companies offer better conditions, I will work there. & 0.821 & 0.303 \\
If I could make a choice again, I would not choose my current company. & 0.783 & 0.391 \\
I am seriously thinking of leaving my current company. & 0.781 & 0.302 \\
I often search job postings of other companies. & 0.704 & 0.358 \\
If I could start again, I would not choose my current occupation. & 0.342 & 0.866 \\
My current company is not an ideal lifetime workplace. & 0.350 & 0.851 \\
If I am paid the same amount, I would take other types of occupation. & 0.389 & 0.837 \\
I want to work in other fields, rather than my current field of my job. & 0.308 & 0.780 \\
Unique value & 3.667 & 3.242 \\
Explained variance (\%) & 40.739 & 38.041 \\
Cumulative variance (\%) & 40.739 & 0.914 \\
Reliability coefficient (Cronbach's $\alpha$ ) & & 0.933 \\
\hline
\end{tabular}

Table 5. Analysis of the effects of human resource management on turnover intention for the same field

\begin{tabular}{|c|c|c|c|c|c|c|}
\hline Model & & B & SE B & $\beta$ & $\mathrm{t}$ & $p$ \\
\hline \multirow{5}{*}{$\begin{array}{l}\text { Human } \\
\text { resource } \\
\text { management }\end{array}$} & (Constant) & 0.000 & 0.032 & & 0.000 & 1.000 \\
\hline & Education management & -0.181 & 0.032 & -0.181 & $-5.679^{* * *}$ & 0.000 \\
\hline & Work management & -0.236 & 0.032 & -0.236 & $-7.416^{* * *}$ & 0.000 \\
\hline & Compensation management & -0.422 & 0.032 & -0.422 & $-13.253^{* * *}$ & 0.000 \\
\hline & Employment management & -0.166 & 0.032 & -0.166 & $-5.197^{* * *}$ & 0.000 \\
\hline
\end{tabular}

adjusted $\mathrm{R}^{2}=0.290 ; F=72.473 ; p=0.000$.

${ }^{* * *} p<0.001 ; \mathrm{B}$, coefficient; SE B, standard error of coefficient.

Table 6. Analysis of the effects of human resource management on turnover intention for different fields

\begin{tabular}{|c|c|c|c|c|c|c|}
\hline Model & & B & SE B & $\beta$ & $\mathrm{t}$ & $p$ \\
\hline \multirow{5}{*}{$\begin{array}{l}\text { Human } \\
\text { resource } \\
\text { management }\end{array}$} & (Constant) & 0.000 & 0.035 & & 0.000 & 1.000 \\
\hline & Education management & -0.191 & 0.035 & -0.191 & $-5.431^{* * *}$ & 0.000 \\
\hline & Work management & -0.264 & 0.035 & -0.264 & $-7.501^{* * *}$ & 0.000 \\
\hline & Compensation management & -0.160 & 0.035 & -0.160 & $-4.543^{* * *}$ & 0.000 \\
\hline & Employment management & -0.088 & 0.035 & -0.088 & $-2.513^{*}$ & 0.012 \\
\hline
\end{tabular}

adjusted $\mathrm{R}^{2}=0.135 ; F=28.179 ; p=0.000$.

${ }^{*} p<0.05 ;{ }^{* * *} p<0.001$; B, coefficient; SE B, standard error of coefficient. 
지식공유의 하위요인들이 이직의도의 하위요인인 동일분야 이직의도에 미치는 영향에 대한 회귀분석 결과는 Table 7과 같 다. 지식저장, 구조적 공유, 관계적 공유, 개인적 공유에서 유의 미하게 영향을 미치는 것으로 나타났고 지식저장, 구조적 공유, 관계적 공유, 개인적 공유 변수가 동일분야 이직의도 요인을 예 측하는데 $21.9 \%$ 의 설명력을 갖는 것으로 나타났다. 독립변수 의 영향력을 살펴보면 지식저장, 구조적 공유, 관계적 공유, 개 인적 공유 변수가 유의미하게 $(p<0.001)$ 부(-)적으로 영향을 미 치는 것으로 나타났다. 이는 지식저장, 구조적 공유, 관계적 공 유, 개인적 공유가 높아질수록 동일분야 이직의도는 낮아지고 있음을 의미한다. 각 변수의 영향력을 살펴보면 구조적 공유( $\beta$ $=-0.350)$, 관계적 공유 $(\beta=-0.231)$, 지식저장 $(\beta=-0.181)$, 개 인적 공유 $(\beta=-0.119)$ 순으로 크게 영향을 미치는 것으로 나타 났다. 이러한 결과는 조직몰입이나 이직의도와 같은 변수들이 지식공유에 영향을 미친다는 Joe (2015)의 연구와 유사함을 확 인하였다.

2) 지식공유가 타분야 이직의도에 미치는 영향

지식공유의 하위요인들이 이직의도의 하위요인인 타분야 이 직의도에 미치는 영향에 대한 회귀분석 결과는 Table 8과 같다. 지식저장, 구조적 공유, 관계적 공유, 개인적 공유에서 유의미하 게 영향을 미치는 것으로 나타났고, 지식저장, 구조적 공유, 관 계적 공유, 개인적 공유 변수가 타분야 이직의도 요인을 예측하 는데 $22.7 \%$ 의 설명력을 갖는 것으로 나타났다. 독립변수의 영
향력을 살펴보면 구조적 공유, 관계적 공유, 개인적 공유 변수가 유의미하게 $(p<0.001)$ 부(-)적으로 영향을 미치는 것으로 나타 났고 지식저장 변수가 유의미하게 $(p<0.05)$ 부(-)적으로 영향을 미치는 것으로 나타났다. 이는 지식저장, 구조적 공유, 관계적 공유, 개인적 공유가 높아질수록 타분야 이직의도는 낮아지고 있음을 의미한다. 각 변수의 영향력을 살펴보면 구조적 공유( $\beta$ $=-0.270)$, 개인적 공유 $(\beta=-0.258)$, 관계적 공유 $(\beta=-0.220)$, 지식저장 $(\beta=-0.208)$ 순으로 크게 영향을 미치는 것으로 나타났 다. 이러한 결과는 지식공유는 이직의도에 유의한 영향을 미친 다는 Kim \& Park (2016)의 연구와 유사함을 확인하였다.

\section{Conclusion}

본 연구는 미용서비스업에서 인적자원관리, 지식공유가 이직 의도에 미치는 영향 관계를 알아보는 것을 목적으로 하였다. 미 용서비스업의 종사자를 대상으로 자료를 수집하였고, 수집된 자 료 700부는 SPSS 22.0을 통해 분석되었다. 분석방법은 빈도분 석, 요인분석, 신뢰도 분석, 다중회귀분석이 사용되었다.

조사대상의 일반적 특성을 알아본 결과, 성별은 여성이, 연령 은 20 대가, 결혼여부는 미혼이, 학력은 대학교 재학/졸업이, 직 급은 인턴이 가장 높게 나타났으며, 급여형태는 급여가, 미용경 력은 3년 이하가, 회사형태로는 프랜차이즈가, 직원 수는 6-10 명이, 미용분야는 헤어가 가장 높게 나타났다.

Table 7. Analysis of the effects of knowledge sharing on turnover intention for the same field

\begin{tabular}{|c|c|c|c|c|c|c|}
\hline Model & & B & SE B & $\beta$ & $\mathrm{t}$ & $p$ \\
\hline \multirow{5}{*}{ Knowledge sharing } & (Constant) & 0.000 & 0.033 & & 0.000 & 1.000 \\
\hline & Knowledge storing & -0.181 & 0.033 & -0.181 & $-5.425^{* * *}$ & 0.000 \\
\hline & Structuring sharing & -0.350 & 0.033 & -0.350 & $-10.468^{* * *}$ & 0.000 \\
\hline & Relational sharing & -0.231 & 0.033 & -0.231 & $-6.916^{* * *}$ & 0.000 \\
\hline & Personal sharing & -0.119 & 0.033 & -0.119 & $-3.557^{* * *}$ & 0.000 \\
\hline
\end{tabular}

adjusted $\mathrm{R}^{2}=0.219 ; F=49.876 ; p=0.000$.

${ }_{* * *} p<0.001 ; \mathrm{B}$, coefficient; SE B, standard error of coefficient.

Table 8. Analysis of the effects of knowledge sharing on turnover intention for different fields

\begin{tabular}{|c|c|c|c|c|c|c|}
\hline Model & & B & SE B & $\beta$ & $\mathrm{t}$ & $p$ \\
\hline \multirow{5}{*}{ Knowledge sharing } & (Constant) & 0.000 & 0.033 & & 0.000 & 1.000 \\
\hline & Knowledge storing & -0.208 & 0.033 & -0.208 & $-6.268^{*}$ & 0.000 \\
\hline & Structuring sharing & -0.270 & 0.033 & -0.270 & $-8.116^{* * *}$ & 0.000 \\
\hline & Relational sharing & -0.220 & 0.033 & -0.220 & $-6.600^{* * *}$ & 0.000 \\
\hline & Personal sharing & -0.258 & 0.033 & -0.258 & $-7.759^{* * *}$ & 0.000 \\
\hline
\end{tabular}

adjusted $\mathrm{R}^{2}=0.227 ; F=52.228 ; p=0.000$.

${ }^{*} p<0.05 ;{ }^{* * *} p<0.001 ; \mathrm{B}$, coefficient; SE B, standard error of coefficient. 
인적자원관리, 지식공유, 이직의도의 차원을 알아보기 위해 요인, 신뢰도를 분석한 결과, 인적자원관리는 교육관리, 직무 관리, 보상관리, 채용관리로 도출되었고, 지식공유는 지식저 장, 구조적 공유, 관계적 공유, 개인적 공유로 도출되었으며, 이직의도는 동일분야 이직의도, 타분야 이직의도로 도출되었 다.

인적자원관리가 이직의도에 미치는 영향을 확인한 결과, 인 적자원관리의 하위요인인 교육관리, 직무관리, 보상관리, 채용 관리가 이직의도의 요인인 동일분야 이직의도 및 타분야 이직 의도에 유의미하게 영향을 미치는 것으로 나타났다. 이를 통해 체계적인 인적자원관리는 종사자들에게 긍정적인 영향을 미치 며 이직의도를 낮추는 중요한 요인임을 확인할 수 있었다.

지식공유가 이직의도에 미치는 영향에 대해서는, 지식공유의 하위요인인 지식저장, 구조적 공유, 관계적 공유, 개인적 공유 가 동일분야 이직의도 및 타분야 이직의도에 유의미하게 영향 을 미치는 것으로 나타났다. 이는 미용서비스업에서도 다른 기 업들과 같이 종사자들 사이의 지식공유활동이 활발히 이루어져 야 한다는 것을 보여주고 있다.

이에 미용서비스업에서는 이직률을 감소시키기 위해서 좀 더 체계적인 인적자원관리와 지식공유에 대한 방안을 제공하도록 노력해야 할 것이며, 본 연구의 결과가 미용서비스업의 발전을 위한 기초자료로 활용되기를 바란다. 또한 본 연구는 미용서비 스업의 종사자로 표본구성을 했으므로 연구 결과를 일반화 시 키는데 제한점이 있으며, 향후 연구에서는 다른 서비스산업과 의 비교분석연구가 이루어지길 기대한다.

This work is part of the Jung-Eun Park's Ph.D. thesis at the Seokyeong University, Seoul, Korea.

\section{References}

Cha YD, Chang YC. SHRM, the HR's department role characteristics and organizational performance. Journal of Creativity and Innovation, 3: 175-221, 2010.

Cho SH, Yoon DY. The relationship between strategic human resource management practices and turnover intention of employees at Korean SMEs (small and mediumsized enterprises): the moderating effect of emotional leadership. Journal of Human Resource Management Research, 20: 285-300, 2013.

Choi SB, Park JC. The effect of inter-firm cooperation and knowledge sharing on firm competitiveness of SMEs: moderating effects of environmental factors. Knowledge
Management Review, 13: 65-89, 2012.

Eom YK. Organizational politics impact on knowledge sharing: focusing on teacher's perceptions of organizational politics and political skill. The Korean Journal of Human Resource Development Quarterly, 16: 207-230, 2014.

Joe S. An empirical study on factors affecting knowledge sharing in organizations: strong relationship, organi zational learning culture, developmental feedback, organizational commitment, and turnover intention. Journal of Agricultural Education and Human Resource Development, 47: 129-153, 2015.

Jun IW. A study on the teachers' intention related factors to leave and attitudes toward teaching profession of the private kindergarten teachers. The Journal of Korea Open Association for Early Childhood Education, 7: 39-52, 2003.

Kang IJ, Jyung CY. The relationships among turnover intention, career related learning, employability, organizational commitment and career commitment of office workers in large corporations. Journal of Agricultural Education and Human Resource Development, 47: 149-175, 2015.

Kim BJ, Kim BD. Publishing business theory. Jigyungsa, Seoul, p189, 1999.

Kim MC, Kang KB. An empirical study on the factors of knowledge sharing. Journal of Finance \& Knowledge Studies, 2: 176-200, 2004.

Kim RK, Park BG. The effects of followership of coffee speciality members on LMX, knowledge sharing, and job attitude. Journal of Digital Convergence, 14: 73-81, 2016.

Kim YA, Han CH, Kim HY. A study on effects of emotional labor organizational commitment: focusing on comparison of nurses between public and private asylums. Korean Public Personnel Administration Review, 14: 133-154, 2015.

Moon IO. The effect of knowledge sharing on innovative behavior and organizational commitment in clinical nurses. Journal of Korean Academy of Nursing Admini stration, 11: 173-183, 2005.

Nam JM, Chun B. The impact of high commitment human resource management on employee attitudes: mediating effects of psychological empowerment. Quarterly Journal of Labor Policy, 12: 57-85, 2012.

Shin WM, Seo HM, Kim TH. The influence of leader's conflict 
management style on leader trust, organizational commitment, turnover intention of professional dancers. The Korean Journal of Physical Education, 54: 475-489, 2015.

Song GR, Kim JG. The influence of strategic human resource management system on intellectual capital and innovative capabilities. Journal of Human Resource
Management Research, 18: 105-127, 2011.

Song KS, Na BS. A study on the relationships among the human resource management factors, job satisfaction, organizational commitment and innovative behavior. Korean Public Personnel Administration Review, 13: 327350, 2014. 


\section{국문초록}

\section{미용서비스업의 인적자원관리, 지식공유가 이직의도에 미치는 영향}

박정은, 박은준

서경대학교 미용예술학과, 서울, 한국

목적: 본 연구는 미용서비스업에서 인적자원관리, 지식공유가 이직의도에 미치는 영향 관계를 알아보고자 한다. 방법: 미용서비스 업 종사자를 대상으로 자료를 수집하였고, Statistical Package for the Social Sciences (SPSS) 22.0을 이용하여 분석하였다. 분석방 법은 빈도분석, 요인분석, 신뢰도 분석, 다중회귀분석이 사용되었다. 결과: 인적자원관리 요인인 교육관리, 직무관리, 보상관리, 채 용관리가 이직의도 요인인 동일분야 이직의도와 타분야 이직의도에 유의미하게 영향을 미치는 것으로 나타났고, 지식공유 요인인 지식저장, 구조적 공유, 관계적 공유, 개인적 공유도 동일분야 이직의도와 타분야 이직의도에 유의미하게 영향을 미치는 것으로 나 타났다. 결론: 본 연구결과가 미용서비스업의 발전을 위한 기초자료로 활용되기를 바라며, 미용서비스업의 이직률을 줄이는 방안 으로 인적자원관리와 지식공유의 중요성을 인식하고 체계적인 전략방안을 수립하여야 할 것으로 사료된다.

핵심어: 미용, 서비스업, 인적자원관리, 지식공유, 이직의도

\section{참고문헌}

강인주, 정철영. 대기업 사무직 근로자의 이직의도와 경력학습, 고용가능성, 조직몰입 및 경력몰입의 관계. 농업교육과 인적자 원개발, 47: 149-175, 2015.

김리경, 박봉규. 커피전문점 직원의 팔로워십이 리더-구성원 교환관계, 지식공유 및 직무태도에 미치는 영향. 디지털융복합 연구, 14: 73-81, 2016.

김민철, 강경범. 지식공유 요인에 관한 실증 분석. 금융지식연구, 2: 176-200, 2004.

김병준, 김병도. 출판 경영론. 지경사, 서울, $\mathrm{p} 189,1999$.

김영애, 한종희, 김혜영. 감정노동에 대한 인식이 조직몰입에 미치는 영향 연구: 공공보건의료기관과 민간의료기관의 정신간

호사를 대상으로 비교분석. 한국인사행정학회보, 14: 133-154, 2015.

남정민, 전병준. 다수준 접근을 통한 고몰입 인적자원관리가 구성원의 직무만족 및 이직의도에 미치는 영향에 대한 연구: 심리

적 임파워먼트의 매개효과 규명. 노동정책연구, $12: 57-85,2012$.

문인오. 간호사의 지식공유가 혁신행동과 조직몰입에 미치는 영향. 간호행정학회지, 11: 173-183, 2005.

송건섭, 나병선. 인적자원관리 구성요소와 직무만족, 조직몰입 및 혁신행동 간의 인과관계. 한국인사행정학회보, 13: $327-$

350, 2014.

송경렬, 김종관. 전략적 인적자원관리 시스템이 지적 자본과 혁신역량에 미치는 영향. 인적자원관리연구, 18: 105-127,

2011.

신원미, 서효민, 김태희. 무용단장의 갈등관리 유형이 단원들의 리더신뢰, 조직몰입, 이직의도에 미치는 영향. 한국체육학회

지, 54: 475-489, 2015.

엄유경. 조직정치가 지식공유에 미치는 영향: 교사의 조직정치지각과 정치적 기술을 중심으로. $H R D$ 연구, $16: 207-230$,

2014.

전일우. 사립유치원 교사의 이직의도 원인 및 이직계획 시기와 직무태도와의 관계연구. 열린유아교육연구, 7: 39-52, 2003. 조성준. 지식공유 의도의 영향요인에 대한 실증적 분석. 농업교육과 인적자원개발, 47: 129-153, 2015.

조세형, 윤동열. 중소기업에서 전략적 인적자원관리와 구성원의 이직의도 간 관계: 감성리더십의 조절효과. 인적자원관리연 구, 20: 285-300, 2013. 
차영덕, 장영철. 전략적 인적자원관리에 있어서 인사부서의 역할이 조직성과에 미치는 영향. 창조와 혁신, 3: 175-221, 2010.

최석봉, 박종찬. 중소기업의 협력활동과 지식공유가 기업경쟁력에 미치는 영향: 기업환경요인의 조절효과. 지식경영연구, $13:$ 65-89, 2012. 


\section{中文摘要}

\section{美容服务业的人力资源管理与知识共享对离职倾向的影响}

朴貞恩, 朴銀俊 ${ }^{*}$

西京大学美容艺术学科, 首尔, 韩国

目的：在美容服务业中，人力资源管理与知识共享对离职倾向的影响。方法：在美容服务业从业人员中，收集资料，并采 用Statistical Package for the Social Sciences (SPSS) 22.0进行统计分析。采用频度分析，因子分析，可靠性分析，多元回 归分析等分析方法来进行数据处理。结果: 教育管理、工作管理、薪酬管理、就业管理等人力资源管理因素对同一领域 或不同领域的离职倾向有显著影响。知识储存、组织共享、关系共享和个人分享等知识共享因素对同一领域或不同领域 的离职倾向有显著影响。结论: 本研究结果将为美容服务业的发展提供了基础数据。为了降低美容服务业的离职率，必 须认识到人力资源管理和知识共享的重要性，并制定系统的战略计划。

关键词: 美容, 服务业, 人力资源管理, 知识共享, 离职倾向 